\title{
Capacitação para quê? $O$ que pensam conselheiros de saúde da região Sudeste
}

\author{
Training for what? What health counselors in the Southeastern \\ region think about the topic
}

Claudia Jurberg ${ }^{1}$

Eloy Macchiute de Oliveira ${ }^{2}$

Eloiza da Silva Gomes de Oliveira ${ }^{3}$

${ }^{1}$ Núcleo de Divulgação do

Abstract Community of Practice (CoP) is a recent term that applies to individuals who share a common goal that can range from a specific theme, a problem or a passion, whereby learning together and the feeling of belonging to the differentials of this theory can reflect positively on the acquisition of knowledge as a participatory process. This article seeks to ascertain the relevance of building a community of practice for health counselors within the policy of the Brazilian Unified Health System (SUS) to enhance popular participation. In this respect, the opinions of 108 health counselors with Internet access in the Southeast of the country were investigated. What are their views on the structure and training within the Health Councils? And what do they consider to be important in order to enhance their performance within the Councils?

Key words Health counselors, Training, Community of practice
Programa de Oncobiologia, Universidade Federal do Rio de Janeiro. Av. Carlos Chagas Filho 373/CCS/ Bloco H2/sala 003, Ilha do Fundão. 21941-902 Rio de Janeiro RJ Brasil. cjurberg@bioqmed.ufrj.br ${ }^{2}$ Datasus, Ministério da Saúde.

${ }^{3}$ Faculdade de Educação, Universidade do Estado do Rio de Janeiro.
Resumo Comunidade de prática (CoP) é um termo recente e que se aplica a individuos que compartilham um objetivo comum que pode englobar desde uma temática específica, um problema ou uma paixão, sendo o aprendizado em conjunto e o sentimento de pertença os diferenciais dessa teoria que pode refletir, positivamente, na aquisição de conhecimento como um processo participativo. Este artigo procura averiguar a pertinência da construção de uma comunidade de prática para conselheiros de saúde dentro da politica do Sistema Único (SUS) de valorizar a participação popular. Nesta direção, investigamos a opinião de 108 conselheiros de saúde da região Sudeste do país e com acesso à Internet. Qual é a visão deles sobre a estruturação e capacitação dentro dos Conselhos de Saúde? E o que acreditam seja importante para melhorar sua atuação dentro dos Conselhos?

Palavras-chave Conselheiros de saúde, Capacitação, Comunidade de prática 


\section{Introdução}

Pensar o Sistema Único de Saúde (SUS) depois da Constituição Federal de 1988, incluindo como seu pressuposto fundamental a saúde como direito significa refletir sobre uma participação política, livre e igualitária de todos os cidadãos.

No processo de construção dos marcos referenciais da saúde, um dos temas centrais foi a inclusão da participação da sociedade como norteador da reforma sanitária. Esta proposição foi afirmada na Constituição e implementada a partir da Lei 8.142/90 com a criação dos Conselhos de Saúde e das Conferências de Saúde ${ }^{1}$. Pereira $^{2}$ afirma que a ideia inicial dos Conselhos de Saúde, como instância democrática, visava, desde sua criação, na década de 90 , em novos centros de poder, decorrentes, principalmente, da descentralização do sistema e, assim, contribuir para incrementar o debate e as demandas da sociedade antes restritas aos gestores do sistema.

Dentro da Lei n. 8.080, de 1990, os Conselhos de Saúde, junto com as Conferências Nacionais de Saúde, trariam as condições de instâncias formais para o exercício do princípio de participação popular. A perspectiva era traçar diretrizes para as políticas de saúde, através da participação dos diferentes atores e segmentos implicados no processo de democratização ${ }^{3,4}$.

De acordo com Macedo 5 , o direito à participação e ao controle social na saúde adveio de um processo histórico marcado por embates entre grupos com interesses diferenciados ${ }^{6}$. Essas ideias do controle social surgiram no bojo do movimento sanitarista, no final dos anos 70 , e se desenvolveram durante o processo de redemocratização empreendido na década seguinte.

Podemos afirmar que o controle social representa um aprimoramento da democracia representativa, permitindo uma maior participação popular na determinação das políticas públicas. Entretanto, pressupõe uma sociedade civil organizada e que responda aos anseios populares.

Atualmente, os Conselhos de Saúde estão implantados na quase totalidade dos municípios brasileiros, mas segundo Correia ${ }^{1}$, são muitos os limites impostos à efetivação do controle social. Dentre os quais, se destaca a tendência neoliberal para o desmonte da política de saúde concebida para o SUS; ingerência política na escolha dos conselheiros; falta de informação dos conselheiros; desarticulação entre os conselheiros e suas bases; a fragilidade da mobilização das entidades representadas que, por sua vez, reflete na desmobilização da sociedade; a cooptação de lideranças em troca de favores; a pouca transparência dos gestores no uso dos recursos. E mais a manipulação dos Conselhos/conselheiros para legitimar gestões; a pouca visibilidade das ações dos conselhos; o descumprimento das suas deliberações por parte dos gestores; a fragilidade do nível de organização dos movimentos populares e sindical; a cultura arraigada de submissão na população brasileira; e não menos importante a baixa representatividade e, consequentemente, a pequena legitimidade dos conselheiros pela pouca organicidade em relação à sua base.

Macedo ${ }^{5}$, por outro lado, ressalta a importância de se sensibilizar os indivíduos para o exercício ético deste controle, visando um compromisso de responsabilidade com os interesses coletivos. Segundo o autor, a falta de clareza sobre a concepção de participação e controle social por parte dos cidadãos é um dos grandes entraves a serem enfrentados pela sociedade para que esta consiga transpor esse limite e exercer o verdadeiro controle social.

Com tantos limitadores, poderíamos questionar se os Conselhos, ao invés de atuarem no controle social, poderiam estar servindo como forma de cooptação dos movimentos sociais para legitimar as políticas públicas propostas pelo gestor da saúde ou por membros mais articulados e bem informados? No entanto, acreditamos que essas limitações são uma decorrência natural do arrojo da proposta e do pequeno tempo decorrido da redemocratização do país. Os Conselhos de Saúde, apesar de terem sido conquistados na luta democrática e de se constituírem em um avanço da saúde sob um prisma contra-hegemônico, na prática, em muitas localidades servem como uma forma de legitimação do poder dominante e até mesmo de cooptação dos movimentos sociais para as causas que reforçam a dominação. Corroboram essa visão Gaedtke e Grisotti ${ }^{7}$ ao questionarem quem realmente são os representantes nos Conselhos de Saúde e de que forma são escolhidos. De acordo com as autoras "o perfil dos representantes nos conselhos desenha uma espécie de elite participativa caracterizada, muitas vezes, por maior renda e escolaridade se comparada à média da população em geral" Isso acarretaria uma dificuldade em se realizar uma "representação representativa." Uma outra questão é, como nos aponta Macedo ${ }^{5}$, que o uso do conselho, muitas vezes, é para endossar decisões não discutidas em seu seio ou interesses de certos conselheiros que representam interesses corporativos. Mas como transformar essa realidade? 


\section{Capacitação dos Conselheiros de Saúde}

São praticamente 30 anos desde a criação do SUS e a capacitação continua sendo um dos gargalos para a efetiva participação e, por conseguinte, o controle social.

Desde a CNS de 1982, a formação e capacitação de conselheiros têm sido apresentadas como propostas nas sucessivas conferências, por se considerar item indispensável ao próprio funcionamento do SUS.

Em 1986, a VIII Conferência Nacional da Saúde já tratava do tema. Entre suas conclusões, apontava não apenas a formação, mas também a reciclagem permanente dos profissionais e recomendava que a formação deveria estar integrada ao sistema regionalizado e hierarquizado. Essas diretrizes acabaram sendo absorvidas pela Constituição. O Inciso III do artigo 200 trata de algumas das atribuições do SUS, nos termos da Lei e determina: "ordenar a formação de Recursos Humanos na área da saúde”. Já o inciso seguinte incentiva o "incremento em sua área de atuação do desenvolvimento científico e tecnológico".

Apenas dois anos após a promulgação da Constituição, a Lei Orgânica da Saúde (1990), volta a mencionar a formação de recursos humanos e o incremento do desenvolvimento científico e tecnológico. Em seu artigo 14, determina que "deverão ser criadas comissões permanentes de integração entre serviços de saúde e as instituições de ensino profissional e superior”, e esmiúça que deverão ser propostos "métodos e estratégias para a formação e educação continuada de recursos humanos em saúde." Segundo Ceccim et al. ${ }^{8}$, essa formação de recursos humanos deve ter como responsáveis as diferentes esferas governamentais.

As IX e X CNS, respectivamente realizadas em 1992 e1996, também trataram do assunto, ressaltando a importância da formação continuada dos profissionais no sentido de se fortalecer o próprio SUS.

Em 2000, durante a XI Conferência, constatou-se que os Conselhos de Saúde careciam, entre outros itens, de formação para assumirem as tarefas decorrentes de uma postura mais ativa de apropriação e uso das informações, refletindo em controle social pouco efetivo. Disso, se concluiu que havia necessidade de promoção da formação dos conselheiros, abrangendo todos os municípios do país. Essa determinação foi atendida em parte pelo Ministério da Saúde, pois em virtude da própria dinâmica dos movimentos sociais, da alta rotatividade dos conselheiros em função da renovação de mandatos com a consequente formação dos novos conselheiros, era necessário uma reciclagem contínua.

Esta Conferência, além de críticas à falta de estrutura e capacitação, aprovou uma proposição que visava "articular a academia, os serviços de saúde, os Centros de Formação de Recursos Humanos das Secretarias de Saúde e Polos de Educação em Saúde para disponibilizar periodicamente, cursos de formação para conselheiros de saúde e usuários do SUS em geral, com inclusão de temas gerais para a melhoria de saúde"

Em 2005, o Conselho Nacional de Saúde (CNS) apresentou em sua plenária um documento denominado "Diretrizes Nacionais para o Processo de Educação Permanente no Controle Social do SUS" que consolidou todas as diretrizes para a formação do controle social até então formuladas em lei, no próprio Conselho Nacional de Saúde e nas Conferências Nacionais de Saúde. Essas diretrizes estabelecem que a educação permanente para o controle social do SUS se daria através de processos formais de transmissão de conhecimento e fóruns de debates, tais como encontros, cursos, oficinas de trabalho, seminários e o uso de metodologias de educação à distância, bem como os demais processos participativos e fóruns de debates. Essas diretrizes recomendavam também a utilização de metodologias que buscassem a construção coletiva de conhecimentos, baseada na experiência do grupo.

Embora haja recomendações suficientes sobre a importância de capacitação no SUS em diferentes instâncias e colegiados, por outro lado, como ressaltam Gaedtke e Grisotti ${ }^{7}$, vários estudos abordam o desconhecimento dos conselheiros sobre o seu papel, o que seria uma das possíveis causas da pouca participação. Assim, conclui-se que há um longo caminho a ser percorrido.

Nesse sentido, acreditamos que a questão ainda merece reflexões como: será que os conselheiros desejam se capacitar? Caso sim, como e para que capacitá-los? e será que a Internet poderia trazer subsídios para uma capacitação efetiva? A seguir, discutiremos alguns aspectos e características de uma comunidade de prática (CoP) como possível ferramenta para a capacitação e, posteriormente, se esta seria válida para aplicação junto a conselheiros de saúde.

\section{Dos primórdios das comunidades às comunidades virtuais}

De acordo com Brancaleone ${ }^{9}$, foi Ferdinand Tönnies (1855-1936), em 1887, quem primeiro 
abordou a questão da comunidade na obra intitulada "Gemeinschaft und Gesellshaft". Segundo Tönnies ${ }^{10}$, comunidade seria uma forma social caracterizada por relações pessoais com intenso espírito emocional, e constituída pela cooperação, costumes e religião. É proporcionada por um relacionamento local, coeso, duradouro, íntimo e face a face.

De forma geral, as comunidades são constituídas por pessoas que vivem dentro de uma determinada área e/ou que são ligadas por objetivos, crenças, aspirações, reconhecimento e compreensão em comum.

"O que caracteriza uma comunidade é que a vida de alguém pode ser totalmente vivida dentro dela. O critério básico de uma comunidade, portanto, está em que todas as relações de alguém podem ser encontradas dentro dela". Isso não quer dizer que todas as comunidades tenham que ser autossuficientes. Uma comunidade, assim, não está necessariamente circunscrita aos limites políticos, "podemos viver em uma grande metrópole e sermos membros de uma comunidade muito pequena ou vivermos numa aldeia e pertencermos a uma comunidade tão grande quanto à área de nossa civilização"11.

Poderíamos então nos perguntar como se dariam, na atualidade, nas grandes cidades, as condições para existência de comunidades, já que nessas o espírito de vizinhança se dá de uma forma infinitamente mais fraca do que na aldeia ou pequena cidade onde todos se conhecem?

Rheingold $^{12}$, ao pensar sobre comunidades virtuais de meados do século passado cita Ray Oldenburg. Oldenburg (1989) propõe no livro "The Great Good Place" a existência de três lugares essenciais na vida: onde vivemos, onde trabalhamos e onde nos reunimos para conviver. Para ele, são nesses "terceiros lugares" onde a comunidade se consuma e se mantém. Então foram esses "terceiros lugares que permitiram que a sociedade moderna mantivesse forte o sentido de comunidade na medida em que permitia às pessoas o senso de lugar comum, onde é possível a convivência, a troca de experiências e a transmissão dos valores".

Ocorre que o que era uma verdade para Tönnis $^{10}$, nos primórdios da revolução industrial, vem se acirrando na sociedade moderna em função da perda desses "terceiros lugares" não apenas por causa do crescimento desordenado das grandes cidades, mas também do aumento das atrações dentro das próprias residências. Ao mesmo tempo em que os lugares de convívio foram desaparecendo, o desenvolvimento das comuni- cações e dos transportes contribuiu para que a noção de territorialidade fosse paulatinamente modificada. $\mathrm{O}$ indivíduo deixou de pertencer a um território restrito onde vivia, trabalhava e tinha o lazer.

Segundo Castells ${ }^{13}$, foi a tecnologia que contribuiu para isso, pois apesar de não determinar a sociedade, sua existência ou a sua falta, incorpora a capacidade de transformação das sociedades bem como os usos que estas decidem dar ao seu potencial tecnológico. Assim foi com a Internet: resultante do amadurecimento e da convergência das tecnologias de telecomunicação e de informática.

A rede foi desenvolvida dentro do projeto americano Arpanet, em 1969. Seu objetivo era manter sua funcionalidade na hipótese de um ataque nuclear. Essa rede logo passou a ser usada também para a troca de mensagens entre indivíduos comuns e, posteriormente, para suportar comunidades virtuais.

O termo "comunidade virtual", para designar uma agregação social ocorrida através da Internet, foi empregado inicialmente por Rheigold ${ }^{12}$ para descrever os "agregados sociais surgidos na rede, quando os intervenientes de um debate o levam adiante em número e sentimento suficientes para formarem teias de relações pessoais no ciberespaço".

Para Rheingold ${ }^{12}$, essa tendência natural à formação de comunidades virtuais possivelmente seja consequência da perda dos "terceiros lugares" descritos por Oldenburg, e, talvez, o ciberespaço seja um dos lugares públicos informais onde possamos reconstruir os aspectos comunitários perdidos.

\section{As Comunidades de Prática (CoP) como um modelo para a busca da comunidade perdida}

O termo Comunidade de Prática (Community of Pratice) $(\mathrm{CoP})$ surgiu a partir de estudos realizados por Etienne Wenger e Jean Lave sobre modelos de aprendizagem. Segundo Wenger ${ }^{14}$, uma CoP deve reunir um grupo de pessoas que compartilham um interesse, um problema que enfrentam regularmente, e que se unem para desenvolver conhecimento de forma a criar uma prática em torno de um determinado assunto

A comunidade de prática $(\mathrm{CoP})$, segundo o autor ${ }^{14}$, não é um "clube" de amigos de uma dessas redes sociais que se espalham na atualidade virtual e muito menos uma simples rede de conexões entre pessoas. Para se tornar uma comunidade é imprescindível que haja uma identidade 
definida através do compartilhamento de domínios de interesse.

Segundo Lave e Wenger ${ }^{15}$, "a CoP não é apenas fonte de conhecimento, mas a participação na prática cultural em que o conhecimento existe como princípio epistemológico da aprendizagem". O conhecimento, nesse caso, não é mais entendido como algo a ser adquirido e sim como um processo de construção participativo e transformador.

Nas CoP, o compartilhamento das experiências obtidas na prática é o mote, e não necessariamente a troca de uma mesma prática. Na verdade, o que encontramos nas comunidades de prática é o compartilhamento do aprendizado sobre as práticas. E pode assim se resumir: "é aprender participando e participar aprendendo".

Ao categorizar, Wenger ${ }^{14}$ afirmava que "comunidades de prática são grupos de pessoas que compartilham uma preocupação ou a paixão por algo que fazem e procuram, dessa forma, estudar como fazer aquilo de forma melhor. Gannon -Leary e Fontainha ${ }^{16}$ complementam ao afirmar que as $\mathrm{CoP}$ podem até ter a aprendizagem como seu principal objetivo, mas o aprendizado onli$n e$, normalmente, acaba por se transformar num efeito colateral dessas. Para De La Rue ${ }^{17}$, o aprendizado baseado numa comunidade possibilita a maior compreensão de um determinado assunto, pois contextualiza os problemas já que seus membros têm afinidades.

O objetivo deste estudo foi identificar junto aos conselheiros de saúde da região Sudeste se o uso de uma CoP poderia contribuir com os processos de capacitação e aprendizagem através de compartilhamento de experiências na utilização de sistemas de informações para o controle social da saúde.

\section{Materiais e Métodos}

Minayo e Sanches ${ }^{18}$ em seu artigo "QuantitativoQualitativo: oposição ou complementaridade" exploram as potencialidades desses métodos para estudos em saúde pública. Segundo os autores, nenhuma das duas abordagens em si é suficiente. Para eles, "um bom método será sempre aquele, que permitindo uma construção correta dos dados, ajude a refletir sobre a dinâmica da teoria".

Baseado nisso, foi elaborado um formulário qualiquantitativo sobre informação e capacitação nos Conselhos de Saúde. Inicialmente, tentamos aplicar pessoalmente nas reuniões dos próprios Conselheiros localizados na baixada fluminense, no Rio de Janeiro. Como esta alternativa não se mostrou eficaz devido à resistência dos membros em colaborar, resolvemos tentar transpor esses impasses através do uso do cadastro de conselheiros de saúde, existente dentro do Sistema de Informação sobre Orçamentos Públicos em Saúde (Siops). Esse sistema foi construído pelo Datasus, a pedido da Controladoria Geral da União (CGU), e se constitui hoje em uma importante ferramenta do controle social. O sistema pode ser acessado através do site www.datasus.gov.br, que foi seu desenvolvedor, o hospeda e é responsável pela sua manutenção.

Em paralelo, optamos por utilizar uma ferramenta disponibilizada pelo Google Docs (https://docs.google.com). Esta ferramenta permite a construção de formulários de pesquisa, a partir de modelos pré-definidos, e depois remetê-los para malas diretas de emails fornecidos. É possível construir formulários com questões de múltipla escolha em diversos formatos e também questões discursivas. $\mathrm{O}$ universo pesquisado recebe o formulário através do seu email. Ao terminar o preenchimento, basta que o respondente aperte um botão "enviar" para que o formulário retorne ao Google Docs, que os disponibiliza em conjunto com os demais formulários recebidos, já tabulados em uma planilha ou já analisado em um relatório.

Ao tentar obter os emails dos conselheiros de saúde, no cadastro obtido no Siops, nos deparamos com a péssima qualidade dos dados ali inseridos, pois não estavam atualizados.

De forma que, em boa parte dos municípios, o único email que aparecia era o da Secretaria de Saúde, ou o do setor de contabilidade. Mesmo no caso dos emails individualizados para cada conselheiro, muitos não eram válidos por estarem errados ou desatualizados.

Então, inicialmente depuramos a lista de conselheiros na região Sudeste. Assim, nosso universo constituiu-se de 12.380 conselheiros de saúde em São Paulo, 10.665 em Minas Gerais, 1.056 no Espírito Santo e 1.592 no Rio de Janeiro, totalizando 25.683 conselheiros. E obtivemos respostas de 43 questionários de 363 destinatários oriundos do Rio de Janeiro. Dos 1.034 formulários enviados para conselheiros de São Paulo, alcançamos resposta de apenas de 18; 37 respostas de um total de 506 e-mails vieram de Minas Gerais e 10 respostas de 195 do Espírito Santo.

Apesar dos percalços do levantamento, conseguimos apurar um total de 108 questionários preenchidos nos quatro estados da região Sudeste, oriundos de 63 municípios. 


\section{Resultados e Discussão}

Dessa amostra de respondentes, 44,1\% eram do sexo masculino. Sobre a formação acadêmica, 1,8\% tinha apenas o Ensino Fundamental; 24,5\% Ensino Médio e a grande maioria $(73,6 \%)$ um curso superior. Vale esclarecer que está proporcionalidade, acreditamos, não espelhe o universo dos conselheiros de saúde, pois como foi captada na Internet, por si só, já é tendenciosa.

Dos respondentes, $8,4 \%$ eram trabalhadores em saúde; $37,8 \%$ usuários, $21 \%$ gestores e 35,8\% não indicaram o tipo de representação.

Além das características sociodemográficas, procuramos averiguar vários aspectos sobre informação e capacitação entre os conselheiros. Inicialmente, os questionamos sobre:

"Em sua opinião, as categorias mais bem informadas têm maior influência nos debates realizados no Conselho de Saúde? Por quê?” Esta questão foi introduzida, a partir de uma presunção de que "informação é poder". No entanto, sabemos que no controle social há controvérsias a esse respeito por se tratar de um discurso pretensamente elitista, que visa excluir dos debates as categorias menos instruídas.

A grande maioria (90\%) dos que responderam concordaram com a relação entre a informação e a influência nos debates. Apenas seis, entre 89 , disseram que não havia influência, argumentando que, mesmo mal informados tecnicamente, eram profundos conhecedores dos problemas dos grupos aos quais representavam e que as posições, dentro do Conselho, são tiradas em um jogo político no qual nem sempre prevalecem os argumentos técnicos. Três dos que responderam, condicionaram a influência ao tipo de discussão que é travada. Ao justificarem suas respostas, outros 17 conselheiros afirmaram que o conhecimento proporciona maior poder argumentativo, colaborando para que as reuniões sejam mais dinâmicas e melhorando os debates. Sete conselheiros apontaram a falta do conhecimento como um dos itens que provoca a inibição entre os participantes, que deixam de manifestarse para não se expor.

Segundo 11 conselheiros, o que está no centro dessa questão é o desconhecimento que o conselheiro tem do seu papel social e da sua capacidade de influenciar as ações de saúde no seu município. Com isso, o gestor e os trabalhadores em saúde acabam dominando os debates, segundo quatro conselheiros.

Para ilustrar o posicionamento dos conselheiros, pinçamos algumas respostas como:
[...] Os secretários de saúde e demais representantes do governo, chegam nas reuniões falando difícil, falando sobre várias siglas, em tom de voz imponente, com vários recursos audiovisuais, lanches etc. e os conselheiros representantes dos usuários geralmente não têm estrutura física dos conselhos para se prepararem. São na grande maioria cidadãos simples, tentam argumentar, mas não têm conhecimento técnico e jurídico. Os regimentos internos são muito confusos. Muitos querem ser conselheiros, mas não se preocupam e se preparam para as reuniões. É um compromisso assumido de livre e espontânea vontade, mas, no entanto, tem que conseguir tempo para exercer tal trabalho voluntário, apesar de achá-lo gratificante.

[...] Sem dúvida os gestores são profissionais e os trabalhadores têm sindicatos com recursos para manter assessoria e apoio administrativo, no entanto, os usuários são fragmentados e sem recursos para se organizarem...

Os menos informados acham que o governo faz favor em realizar os serviços, as obras, o atendimento ao povo. Isso mostra, na minha opinião, que eles não sabem diferenciar quais são as obrigações do Estado e qual a parcela de participação do cidadão no controle social.

As respostas parecem evidenciar, o que se apresenta como mais óbvio, a fragilidade da participação nos Conselhos de Saúde, do homem simples e não detentor de conhecimentos refinados sobre saúde pública, legislação e gestão, pois essa exigência inviabiliza sua participação cidadã como conhecedor dos problemas da sua comunidade. Soma-se a isso, por outro lado, a debilidade também no controle social em saúde, pela falta ou dificuldade de articulação desses membros do conselho, muitas vezes, com a própria comunidade local ${ }^{19}$. No entanto, numa análise mais detida sobre a questão, percebemos que os movimentos sociais precisam ser fortalecidos de forma a municiar seus representantes do conhecimento e da assessoria técnica e jurídica necessárias. Capacitar conselheiros é suprir uma lacuna deixada pelos movimentos sociais.

A questão "Em sua opinião, a falta de informações/conhecimento por parte dos conselheiros cria dificuldades para que o conselho exerça se papel social? Quais dificuldades?" foi adicionada à pesquisa para captar o sentimento dos conselheiros sobre a efetividade do conselho em função da deficiência de informações/conhecimentos, mas por se parecer um pouco com a questão anterior, que visava conhecer a influência desses fatores nas relações entre os diversos interesses, às vezes divergentes, no conselho, muitos respon- 
deram de forma semelhante. Mesmo assim pudemos aproveitar boa parte das respostas. Dos 84 conselheiros de quatro estados que responderam a esta questão, 77 concordaram que a falta de conhecimento tenha efetividade no cumprimento do seu papel social. Apenas cinco conselheiros não concordaram com esta afirmativa.

Um deles disse: Não porque o grupo se interagem (sic) e esta se atualizando e buscando novas informações. (Rio de Janeiro)

Entre aqueles que concordam com a afirmativa, podemos ressaltar o seguinte depoimento:

[...] Sim, com certeza. A falta de informações e conhecimentos de um conselheiro gera uma dificuldade de expressão e insegurança e claro isso influencia no desempenho da sua atuação dentro do conselho. (São Paulo)

Estas afirmativas corroboram com os dados levantados já que 13/77 responderam que aqueles com mais informação acabam conduzindo as discussões dentro do Conselho:

[...] Quando você tem a informação correta, sobre o assunto que vai deliberar e tem que ficar cara a cara com o gestor do SUS, cobra explicações e este vai the respeitar. Mas a maioria dos conselheiros são (sic) pessoas simples, com poucos estudos, porque as camadas da sociedade, com certo poder financeiro, desconhecem o conselho municipal de saúde, geralmente usam o plano de saúde e não o SUS. Vejo este fato, principalmente, nos pequenos municipios. Os conselheiros eleitos imaginam que vão apenas fiscalizar pequenas denúncias contra falta de medicamentos, falta de humanização da medicina etc., mas quando são obrigados a deliberar e votar sobre outros assuntos como relatório de gestão, que tem várias partes como pacto pela saúde, que está atrelado ao plano Diretor de Saúde do município, tem informações no Siops, do Datasus, na sua grande maioria desconhece todos estes fatos. Diante do exposto, acabam aprovando irregularidades grotescas, e não conseguindo assim corrigir possíveis desvios. ( Minas Gerais)

É curiosos notar que entre 77 respondentes, 12 afirmaram que situações como essa acabam provocando um atrelamento ao gestor; outros 13 acrescentaram que essa falta de conhecimento ainda dificulta ou atrasa o debate para as prestações de contas dos gestores ou de algum projeto do interesse do município enviado pelo gestor.

Para a indagação sobre a opinião dos conselheiros sobre "Se a maioria dos conselheiros de saúde tem informações/conhecimentos necessários para o exercício das suas funções”. Do total de respondentes (108), 95 (90,4\%) disseram que não. Por mais que possa parecer meio obvio para quem exerce suas funções na área da saúde, a ideia desse questionamento era verificar como os conselheiros se autoavaliam. Por incrível que pareça, o resultado deste questionamento, trouxe manifestações muito interessantes como:

[...] a resposta acima refere-se a minha situação e acho que a da maioria não é diferente. Quando assumi como conselheira, nem sabia que existiam conselhos de saúde, quanto mais atribuições. Hoje, sei um pouco, mas mesmo assim acho que ainda falta muito chegar lá. Acho que o que atrapalha muito é que o povo brasileiro não tem costume de participar das ações do governo, não só da saúde. (Espírito Santo)

Do mesmo estado, transcrevemos outro depoimento:

[...] A capacitação para os conselheiros de saúde, quando ocorre é incipiente, e a cidadania não pode ser adquirido (sic) de um dia para outro, deve-se trabalhar uma educação permanente na população, no intuito de eleger cidadãos com um mínimo de nível de conhecimento. (Espírito Santo)

De uma forma geral, as respostas a esta questão vão além da confirmação do que esperávamos em relação ao desconhecimento dos conselheiros sobre suas próprias atribuições (13/108). $\mathrm{Na}$ tentativa de identificar a raiz do problema, os conselheiros apontam questões estruturais, como a falta de educação básica (14/108) e de educação para a cidadania, ou para a pouca legitimidade do próprio conselheiro que, em muitas ocasiões, é indicado para o Conselho pela sua entidade. Um bom exemplo veio de um conselheiro de Minas Gerais:

[...] Penso: que a educação tem de vir a partir do ensino fundamental, curso de cidadania. Grande parte dos conselheiros entram (sic) para o conselho sem conhecimento algum e fica (sic) dois anos para aprender. Alguns ficam e outros saime (sic) o conselho continua frágil. Precisamos investir mais na educação do cidadão. As escolas de saúde só capacitam trabalhadores da saúde e deixam de lado o cidadão; o conselheiro deveria ter curriculum base para se candidata, porriso (sic) temos que cria cursos de capacitação de cidadania... obs: sou deficiente visual. (Minas Gerais)

Esta indicação para o Conselho se dá, muitas vezes, pelo simples fato de estar disponível e não por seu engajamento na luta social da saúde, provocando com isso inadequação para a função, desqualificação e o consequente desinteresse (8/108).

[...] as dificuldades, principalmente no setor de usuários, são enormes, pois todos dependem de doar seu tempo de trabalho, família, para se dedi- 
carem ao conselho e o governo não está nem aí, em contra partida (sic) os profissionais e gestores utilizam seu tempo do trabalho que já ganham, para se dedicarem ao conselho, isso quando acontece. (Rio de Janeiro)

Em relação às dificuldades esperadas pelos conselheiros de saúde, caso fosse implantado um grupo de estudo, através da Internet para a troca de informações por escrito, 56\% apontaram o tempo, seguido pela disponibilidade (47\%). A dificuldade com o uso da tecnologia vem em terceiro lugar com $45 \%$. O acesso a computadores aparece em $43 \%$ das respostas e a dificuldade com a comunicação escrita foi o único item a discrepar com apenas 19\%. Cabe ressaltar que esta questão foi elaborada, possibilitando ao conselheiro responder a múltiplas opções. Por esse motivo, encontramos percentuais muito próximos entre as opções, a exceção com a comunicação escrita, para a qual os conselheiros parecem ter dado uma menor importância. Sobressai este resultado em virtude de temos encontrado diversos erros na construção das frases nas questões qualitativas. $\mathrm{Ou}$ os conselheiros, realmente, não dão importância a isso, ou não têm consciência dos limites da sua escrita, pois muitas vezes, tivemos que reler as respostas para tentarmos entendê-las.

Quando questionado sobre a adesão que teria entre os conselheiros de saúde a criação de um site na Internet para a troca de informações, obtivemos, numa escala de Likert, um quadro bimodal, fortemente concentrado no maior nível e no nível intermediário (ambos com 34\% das respostas).

Como reconhecemos a tendência central nas respostas dadas numa escala de Likert, podemos concluir que, na opinião dos conselheiros de saúde, haveria uma forte adesão à criação do site.

Ao justificarem suas respostas, 20 dos conselheiros revelaram apreensão quanto à dificuldade advinda da baixa escolaridade e da limitação no uso do computador e da Internet. O custo de acesso à Internet também foi lembrado em cinco respostas.

No entanto, 27 respondentes afirmavam acreditar que a adesão seria justificada pelo aumento na troca de experiência, informações e conhecimentos e pela aprendizagem proporcionada.

Como esta questão permitia que o conselheiro, caso quisesse, se expressasse mais, transcrevemos o seguinte depoimento ilustrativo:

[...] Sou Conselheiro apenas 3 meses. Não recebi até hoje nenhum treinamento da Gerência Regional de Saúde, e já tive que deliberar sobre vários assuntos como PAVS, Relatório de Gestão e tudo sem nenhum treinamento e com má vontade por parte das Secretarias de Saúde [...] Para os gestores do SUS, a nível municipal, pelo que observo, quanto maior for a falta de qualificação dos conselheiros em fiscalizar e de onde buscar as informações corretas, será melhor para os gestores do SUS poderem manipular as conselheiros facilmente. (Minas Gerais)

Além dos tópicos acima, esta pesquisa propôs ainda aos conselheiros oito ramos do conhecimento que julgamos relevantes para a prática de sua atividade e pedimos que assinalassem numa escala de Likert, em sua opinião, o grau de importância. Os resultados podem ser observados nas Tabelas 1 e 2 . Acreditamos que esse resultado não pode ser visto como uma espécie de currículo mínimo para a capacitação, uma vez que a realidade da saúde e da prática do controle social em cada município aponta para necessidades específicas. Enquanto o grande problema de saúde, para alguns, passa pelo saneamento básico, para outros está centrado na quantidade de leitos de CTI.

A questão número 7 intitulava-se " $\mathrm{Na}$ sua opinião, qual o conhecimento que um Conselheiro de Saúde deva ter sobre os tópicos abaixo" sob a metodologia de escala de Likert, disponibilizando apenas opções positivas, sendo 1 igual a "nenhuma" e 5 igual "muito grande.

Tabulamos a distribuição das frequências para cada categoria ( 1 a 5 ) e as multiplicamos pelos pesos 1 a 5 de acordo com a valoração da categoria. Essa multiplicação teve como objetivo dar maior valor às frequências de maior peso. Somamos os resultados acima para cada quesito e fizemos um ranking. As tabelas 1 e 2 nos mostram

Tabela 1. Distribuição da frequência de resposta numa Escala de Likert.

\begin{tabular}{|c|c|c|c|c|c|}
\hline \multirow[b]{2}{*}{ Temas } & \multicolumn{5}{|c|}{ Escala de Likert } \\
\hline & 1 & 2 & 3 & 4 & 5 \\
\hline Informações em saúde & 0 & 2 & 21 & 33 & 53 \\
\hline Legislação & 0 & 5 & 28 & 34 & 40 \\
\hline Organização do SUS & 0 & 2 & 13 & 35 & 59 \\
\hline Atribuições do CS & 0 & 3 & 2 & 18 & 88 \\
\hline Contabilidade de município & 1 & 7 & 46 & 23 & 40 \\
\hline $\begin{array}{l}\text { Experiências bem sucedidas } \\
\text { em saúde }\end{array}$ & 5 & 5 & 41 & 30 & 24 \\
\hline $\begin{array}{l}\text { Experiências bem sucedidas } \\
\text { em outros conselhos }\end{array}$ & 0 & 5 & 21 & 39 & 41 \\
\hline Noções sobre problemas de saúde & 0 & 3 & 10 & 47 & 52 \\
\hline
\end{tabular}

Legenda: Respostas dos Conselheiros de Saúde com valoração dentro de uma Escala de Likert sobre temas que consideram importante para compreensão do SUS. 
Tabela 2. Ranking dos temas que os Conselheiros de Saúde consideram importantes para compreensão do SUS.

\begin{tabular}{lrrrrrrrr}
\hline & \multicolumn{9}{c}{ Escala de Likert } & & \\
\cline { 2 - 6 } \multicolumn{1}{c}{ Temas } & $\mathbf{1}$ & $\mathbf{2}$ & $\mathbf{3}$ & $\mathbf{4}$ & $\mathbf{5}$ & & soma & ranking \\
\hline Informações em saúde & 0 & 4 & 63 & 132 & 265 & 464 & 4 \\
Legislação & 0 & 10 & 84 & 136 & 200 & & 430 & 7 \\
Organização do SUS & 0 & 4 & 39 & 140 & 295 & & 478 & 3 \\
Atribuições do CS & 0 & 6 & 6 & 72 & 440 & 524 & 1 \\
Contabilidade de município & 1 & 14 & 138 & 92 & 200 & 445 & 5 \\
Experiências bem sucedidas em saúde & 5 & 10 & 123 & 120 & 120 & 378 & 8 \\
Experiências bem sucedidas em outros conselhos & 0 & 10 & 63 & 156 & 205 & & 434 & 6 \\
Noções sobre problemas de saúde & 0 & 6 & 30 & 188 & 260 & & 484 & 2 \\
\hline
\end{tabular}

Legenda: Multiplicação da frequência de respostas dos Conselheiros de Saúde (na Tabela 1) pelo índice de 1 a 5 na Escala de Likert.

que o item mais importante seria conhecer mais sobre Atribuições do Conselho de Saúde, seguido por Noções sobre problemas de saúde, Organização do SUS. O menor interesse entre esses conselheiros recaiu sobre o item Experiências bem sucedidas em saúde, antecedido por Legislação do SUS.

Este ranqueamento, em nossa opinião, reflete exatamente o sentimento capturado nas questões qualitativas, validando o instrumento que, ao repetir de forma diferenciada os mesmos temas, obteve respostas similares. A exceção foi em relação ao item Contabilidade do município. Talvez, o uso deste termo, tenha induzido os respondentes a uma rejeição, pois nas questões qualitativas despertou grande interesse.

"Quais outros conhecimentos são necessários a um conselheiro de saúde?”. Esta questão foi introduzida a fim de refinarmos a compreensão sobre os pontos nos quais, na visão deles, seria necessário investir. Nas questões iniciais sobre esse assunto, nós induzimos as repostas ao definirmos o que era importante e solicitarmos apenas que o conselheiro atribuísse um grau de importância para cada uma das áreas. Com essa questão aberta, foi possível conferirmos se tratamos de todas as categorias e quais outras seriam importantes em um programa de capacitação.

Curioso observar que obtivemos respostas similares aos mesmos itens que havíamos proposto, mas com enfoque no próprio município. Dessa forma, o conselheiro deseja conhecer melhor pontos como funcionamento da saúde no município, orçamento e prestação de contas da prefeitura, as demandas da população, os problemas na gestão da saúde, a estrutura da saúde e a análise de indicadores municipais em saúde.

Ao analisarmos o conjunto de respostas $(\mathrm{N}=$ 108) a essa questão, conseguimos identificar oito categorias. A observação desses resultados deve levar em conta serem essas categorias puramente analíticas, não se traduzindo automaticamente em um possível programa, visto que, muito do conhecimento aí descrito é altamente interdependente. Por exemplo: não podemos falar em políticas públicas em saúde sem mergulharmos no que o SUS representa nessa área.

São as seguintes as categorias:

1. Sistema Único de Saúde - (23 citações) Inclui aspectos como a legislação do SUS e a sua organização nas três esferas de governo, com ênfase para a organização especifica na qual ocorra a capacitação. As pactuações na Tripartite e na Bipartite e as regras de financiamento do SUS.

2. Saúde no município - (19 citações) Aborda questões como informações em saúde e o conhecimento do município nos diversos aspectos do interesse da saúde.

3. Orçamento e gestão em saúde - (18 citações) agregamos itens como contabilidade pública, orçamento da União e municipal para saúde, gastos municipais com a saúde, legislação para licitações, compras públicas e princípios de administração pública.

4. Politica, ética e cidadania - (11 citações) são demanda por conhecimentos sobre política, cidadania, ética, responsabilidades individuais e coletivas, a participação popular e a mobilização e comunicação em saúde.

5. Conselhos de Saúde e Conselheiros - (10 citações) agrega as questões relativas aos diplomas legais dos Conselhos de Saúde e às prerrogativas e responsabilidades dos conselheiros.

6. Políticas públicas em saúde - (4 citações) contém questões sobre os processos de formulação e de acompanhamento de políticas relativas à saúde pública.

7. Informática e Internet - (3 citações) incorpora as demandas por conhecimento em infor- 
mática básica e navegação na Internet, principalmente nos sites onde o conselheiro é capaz de obter informações em saúde, leis, portarias, etc

8. Outros - (3 citações) aqui agregamos a demanda dos conselheiro por conhecimentos mais aprofundados tais como sociologia, economia e psicologia social.

Observe que, com exceção das categorias "política, ética e cidadania", "informática e Internet" e "outros", as demais já haviam sido apresentadas na forma das questões com escalas de Likert, o que, de certa forma, valida as categorias anteriormente propostas.

O formulário também procurou averiguar o perfil do usuário em relação à participação em programas de capacitação e como usuário de Internet. $\mathrm{O}$ resultado encontrado mostrou que a maioria $(53,8 \%)$ afirmou que já tinha participado de curso. Entre os que responderam sim, os questionamos se o programa atendeu suas expectativas. Apenas seis conselheiros responderam que plenamente. A maioria apontou o aproveitamento nesses cursos no nível intermediário de uma escala de Likert de 1 a 5 .

Ainda fomos investigar se já havia participado de um grupo de estudo, $49 \%$ afirmaram que sim. Também o indagamos se já tinha participado de algum fórum virtual. Quanto a isso, 36,7\% afirmaram positivamente e, entre estes, a maioria confirmou ter obtido uma melhoria no conhecimento.

Quanto à habilidade para navegação na Internet, $96,8 \%$ afirmaram que se sentem confortáveis. Entre estes, $89 \%$ navegam diariamente na Internet, sendo que $48 \%$ o fazem de suas residências, $39 \%$ da sede do trabalho, $9 \%$ da sede do Conselho e apenas $0,5 \%$ acessam por meio de lan house.

Entre as ferramentas mais citadas, sintetizamos as seguintes: $22,4 \%$ utilizam email; $15 \%$ utilizam ferramentas de busca; 10,5\% frequentam redes sociais. E quanto aos programas de computador, os conselheiros citaram o editor de texto (38\%); gerador de apresentações $(23 \%)$ e planilhas (22\%).

\section{Colaboradores}

C Jurberg, EM Oliveira e ESG Oliveira participaram igualmente de todas as etapas de elaboração do artigo.

\section{Conclusões}

Este estudo foi importante para avaliarmos qual é a opinião de uma parcela de conselheiros de saúde tanto sobre sua atuação dentro do contexto da participação social no SUS como em relação à capacitação, e se uma ferramenta como uma CoP teria aceitação junto a esses atores. Foi relevante identificar a opinião desses conselheiros de saúde e verificar que, particularmente, entre o grupo estudado, uma ferramenta do tipo CoP poderia ser útil, mesmo ciente da existência entre eles de muitos analfabetos digitais. Como Mengelli ${ }^{20} \mathrm{ex}-$ plica, no processo de uma CoP existe a participação periférica legitimada. É como uma cebola em camadas, onde os novatos constituem a periferia e acabam aprendendo com os mais experientes que compõem o "miolo". Lave ${ }^{21}$ complementa com o que identificou como "prática social situada", na qual a cognição e a comunicação situam-se no desenvolvimento de uma atividade participativa.

A riqueza das respostas dessa amostra foi para nós o grande diferencial deste estudo que, na verdade, acreditamos não se esgotar em si mesmo. Cremos veementemente que novos estudos sobre a temática capacitação de conselheiros de saúde devam ser realizados Brasil afora, identificando a conveniência ou não da implantação de CoP para conselheiros de saúde.

Apesar de nossa amostra só ter contemplado os "alfabetizados" digitais, aqueles que responderam à enquete mostraram um forte interesse pela capacitação. Assim, acreditamos que as $\mathrm{CoP}$ possam ser uma importante aliada na democratização das discussões sobre assuntos correlacionados aos Conselhos de Saúde, ao SUS de forma ampla, contribuindo nessa longa trajetória de amadurecimento de um Sistema que seja universal, integral, descentralizado e que busca a equidade com a participação popular e, como nos disse Soares e Trincaus ${ }^{4}$ que "transforme monólogos em diálogos, pois ainda se observa um descompasso entre teoria e prática na vivência dos Conselhos". 


\section{Referências}

1. Correia MCC. Desafios para o controle social. Subsídios para a capacitação de conselheiros de saúde. Rio de Janeiro: Editora Fiocruz; 2005.

2. Pereira MF. O controle social e a participação democrática nos conselhos municipais de saúde da RIDE DF [tese]. Brasília: Universidade de Brasília; 2010

3. Guizardi F, Pinheiro R, Mattos RA, Santana AD, Matta G, Gomes MCPA. Participação da comunidade em espaços públicos de saúde: uma análise das conferências nacionais de saúde. Physis 2004; 14(1):15-39.

4. Soares LG, Trincaus MR. Participação e controle social: uma revisão bibliográfica dos avanços e desafios vivenciados pelos conselhos de saúde. Rev. Eletrônica Lato Sensu 2007; 2(1):245-264

5. Macedo LC. Participação e controle social na área de saúde: uma revisão bibliográfica [dissertação]. Ribeirão Preto: Escola de Enfermagem de Ribeirão Preto; 2005.

6. Oliveira AMC, Iannu AMZ, Dallari SG. Controle social no SUS: discurso, ação e reação. Cien Saude Colet 2013; 18(8):2329-2338.

7. Gaedtke KM, Grisotti M. Os Conselhos Municipais de Saúde: uma revisão da literatura sobre seus limites e potencialidades. Rev. Pol. e Soc. 2011; 10(19):115-137.

8. Ceccim RB, Armani TB, Rocha CF. O que dizem a legislação e o controle social em saúde sobre a formação de recursos humanos e o papel dos gestores públicos, no Brasil. Cien Saude Colet 2002; 7(2):373-383.

9. Brancaleone C. Comunidade, sociedade e sociabilidade: revisitanto Ferdinand Tonnies. IUPERJ. [serial on the Internet] 2009 [acessado 2009 set 2009]. Disponível em: www.iuperj.br/publicacoes/forum/csoarres.pdf.

10. Tönnis F. Comunidades e sociedades como entidades típico-ideais. In: Fernandes F, organizador. Comunidade e sociedade: leituras sobre problemas conceituais, metodológicos e de aplicação. São Paulo: Cia. Ed. Nacional. Edusp; 1973. p. 96-116.

11. MacIver RM. Comunidad - estudio sociológico. Buenos Aires: Editorial Lousada; 1944.

12. Rheingold H. A Comunidade virtual. Lisboa: Gradiva; 1993.
13. Castells M. A Sociedade em rede. São Paulo: Editora Paz e Terra; 1999.

14. Wenger E. Communities of practice a brief introduction. 2006. [acessado 2014 set 1]. Diponível em: https://scholarsbank.uoregon.edu/xmlui/bitstream/ handle/1794/11736/A\%20brief\%20introduction\%20 to $\% 20$ CoP.pdf?sequence $=1$

15. Lave J, Wenger E. Situated learning: Legitimate peripheral participation. Cambridge: Cambridge University Press; 1991.

16. Gannon-Leary P, Fontainha E. Communities of practice and virtual learning communities: benefits, barriers and success factors. [acessado 2014 set 1]. Diponível em: http://papers.ssrn.com/sol3/papers.cfm?abstract_ $\mathrm{id}=1018066$

17. De La Rue. The theory and practice of communities. KM Review 2008; 11(5):22-25.

18. Minayo C, Sanches O. Quantitativo-Qualitativo: oposição ou complementaridade. Cad Saude Publica. 1993; 9(3):239-362.

19. Shimizu HE, Pereira MF, Cardoso AJC, Bermudez XPCD. Representações sociais dos conselheiros municipais acerca do controle social e em saúde no SUS. Cien Saude Colet 2013; 18(8):2275-2284.

20. Mengelli NM. Interações, redes e comunidades de prática (CoP): subsídios para a gestão do conhecimento na educação [dissertação]. São Paulo: Pontifícia Universidade Católica de São Paulo; 2006.

21. Lave J. Situated learning in communities of practice. In: Resnick LB, Levine JM, Teasley SD, editores. Perspectivs on Socially Shared Cognition. Washington: American Psychological Association; 1993. p. 63-82.

Artigo apresentado em 26/08/2013

Aprovado em 30/11/2013

Versão final apresentada em 09/12/2013 